\title{
EL ESPACIO GEOGRAFICO Y LA PLANIFICACION ESPACIAL
}

\section{Por: Omar Pedraza Ortega*}

El concepto de espacio, que hasta hace algunas décadas evocaba sólo un concepto geométrico, complementado inmediatamente con téminos como «euclidiano», «isotrópico» o «infinito», y que dependía sólo de la matemática; se aborda hoy des de diferentes puntos de vista y ramas del conocimiento hasta llegar a ser «banal» como lo dice Francois Perroux. ¿Quién de nosotros, a lo largo de nuestra vida académica no ha escuchado mencionar la palabra espacio, pero definida como un Sustantivo? En estas condiciones se habla del espacio temporal de los historiadores, el espacio económico de los econom is tas, o el es pacio social tan de moda; y de nuestro espacio: el espacio geográfico.

No sólo los científicos utilizan el término espacio, también el hombre de la calle, quien hace referencia a este concepto considerándolo un bien raro y escaso. Sin embargo, ¿cómo pasar entonces de los espacios matemáticos, es decir de las capacidades mentales de la especie humana, de la lógica, a la naturaleza primero $y$, luego, a las dinámicas que se desarrollan en el espacio? El lograr esta percepción, nos conduce a una concepción eminentemente geográfica del espacio, diferenciado por la distancia y personalizado mentalmente por cada persona.

En las diversas formas que asume la teoría del desarrollo, el concepto de espacio se trata de muy diferentes maneras, contribuyendo a precisar los alcances reales y las limitaciones que en términos de las regiones supone el ejercicio aplicado de la planificación regional.

Las reflexiones sobre los vínculos entre el espacio y el desarrollo, llevan a precisar categorías analíticas que encuentran en la definición y delimitación de regiones geográficas el marco propicio para la acción de planificar y estimular el desarrollo, convirtiéndolas en los sujetos fundamentales de la organización del espacio a la solución de los cuales deben aplicarse las técnicas a disposición del «planificador».

Partiendo del hecho de que toda actividad económica, social, cultural y política se realiza en un espacio geográfico, la organización del espacio como hecho voluntario, es la acción tendiente a implantar sobre el espacio geográfico la planeación del desarrollo. Ello supone pues un conjunto de acciones tendientes a la adecuación del medio físico natural y el creado por las necesidades derivadas de un plan de desarrollo socioeconómico.

El es pacio geográfico es un área donde se conjugan elementos de la naturaleza y las acciones del hombre para satisfacer las necesidades de la sociedad. Por sí mismo ofrece a sus habitantes variadas posibilidades según el grado de

\footnotetext{
* Profesor Universidad Pedagógica Nacional 
organización económica y el nivel tecnológico que posea. La gama de posibilidades está de hecho en función del recurso) base natural.

El espacio geográfico se caracteriza por su extensión, sus lugares, sus distancias, su accesibilidad y sus diferentes interrelaciones. A un micro-nivel, el espacio es un concepto especializado, el mismo) que, al entrar a macronivel, se transforma en un es pacio globalizado. Se hace neces ario precisar en este aspecto la noción de escala.

El espacio es un conjunto indisociable en el que participan loor un lado, cierta combinación de objetos geográficos, objetos naturales y objetos sociales, y, por otro, la vida que los colma y anima, es decir, la sociedad en movimiento. El contenido (la sociedad) no es independiente de la forma (los objetos geográficos), y cada forma encierra una fracción del contenido. El espacio, por consiguiente, es un conjunto de formas, cada una de las cuales contiene fracciones de la sociedad en movimiento. (Puyol:1988)

El espacio es, pues, plasmado por la sociedad; es el producto del desarrollo de ésta en un territorio dado. En la evolución de la sociedad cada uno de sus elementos desempeña un papel al valorizar la naturaleza y facilitar su utilización por parte de la población: los niveles de valorización y de utilización crean categorías disímiles, de donde se deducen niveles jerárquicos de espacios, precisamente como consecuencia de la inequidad de oportunidades que se dan en la relación hombre- naturaleza.

Notoria es la importancia que ha tenido, de manera consciente o inconsciente, el espacio geográfico para la especie humana. El espacio interviene de diferentes maneras en la vida social, en la que cada uno de sus elementos desempeña un papel valorizando la naturaleza y facilitando su utilización por parte de la población; así:

- es el soporte de la vida y de la actividad e interviene por su extensión

- es obstáculo o incentivo de la vida de relación.

- sirve de base a la actividad simbólica.

- precisa las relaciones de inequidad que se dan en la relación hombrenaturaleza.

El espacio interviene primero por su extensión, luego por su función. Puede constituir un elemento activo de combinaciones productivas, como en la agricultura, la ganadería, la exploración forestal, la minería, la pes ca, etc., o puede ser más o menos explotado, o ser destruido. Igualmente, el espacio geográfico puede constituir solo soporte para la implementación de equipamientos diversificados tales como áreas recreacionales, vías de transporte, vivienda, etc. En la mayoría de los casos, estas dos características del espacio, extensión o función se y es tanto un elemento activo de combinación productiva como un soporte. Es el caso, por ejemplo, del espacio urbano. 
Como obs táculo a la vida de relación, el espacio explica que el transporte de los bienes sea costoso, que el de las personas en ocasiones sea difícil y lento. Es por eso que la arquitectura espacial de las sociedades está estrechamente ligada a la tecnología de los transportes, que condiciona la intensidad de los flujos de bienes y servicios que se intercambian nomalmente.

Igualmente, el espacio dificulta la transmisión de las informaciones; cuando la comunicación es directa, la calidad de la relación entre dos grupos es alta. Cuando la comunicación es indirecta a medida que la distancia crece y que aumenta el número de intermediarios, la información se va empobreciendo. Sin embargo, el problema de los transportes y las comunicaciones no es solo técnico sino también económico. Como la sociedad no puede dedicar una parte demasiado grande de sus medios para as egurar el movimiento de bienes y personas, se ve obligada a estructurar redes donde la concentración favorece ciertas partes del espacio respecto de otras.

El espacio como soporte de la actividad simbólica, es percibido de manera muy diferente por sus habitantes:

ellos tienen una imagen mental del espacio donde viven, hecho que les permite entender la configuración de pequeños grupos, su dinámica interna, y las fricciones que los limitan. El hecho antes citado es planteado por Kewin Lynch, en su obra «Imagen de la ciudad», en la que analiza el espacio mental de la ciudad, basándose en tres componentes: identidad, estructura y significado.

Los niveles de valoración y de utilización del espacio, conllevan la necesidad de reorganizar las funciones en las diferentes fracciones del territorio. Cada punto del espacio se torna importante en potencia o en los hechos y su importancia se deriva de sus propias potencialidades, ya sean naturales o sociales. Las diferencias de los factores geográficos que definen el espacio adquieren importancia y distintos niveles jerárquicos cuando se muestran cambios significativos en el orden espacial.

Puede decirse, por lo tanto, a propósito de éstas nuevas realidades, que tales utilizaciones especializadas del territorio, ya sean originalmente naturales 0 culturales o provengan de intervenciones políticas y técnicas, implican un verdadero redescubrimiento de la naturaleza, o cuando menos una revalorización total, en la que cada parte, cada lugar recibe una nueva función, adquiere un nuevo valor.

Precisar las condiciones de inequidad que se dan en la relación hombrenaturaleza nos permite ver que las transformaciones que se producen en el interior de cada espacio no afecta por igual ni con la misma rapidez a todos sus elementos (la distribución del poblamiento, es por ejemplo, más duradera que la de los cultivos o las industrias sin llegar a la lenta evolución de las condiciones ecológicas), siendo también discontinuas en el tiempo pues a períodos de relativa estabilidad les suceden otros de cambios acelerados y profundos, permitiéndonos 
establecer que el grado de organización intema o de entropía varía notablemente de un espacio a otro).

El es pacio tiene un papel fundamental en la estructuración social, es decir, en la reproducción de las relaciones sociales. El espacio es de hecho una dimensión de los mecanismos de transformación, de la práctica de los grupos humanos, de sus relaciones. Contribuye a producir, reproducir y transformar los modos de producción. Es entonces una dimensión activa del diario discurrir de las sociedades, respecto de los cuales Emilio Durkheim afirma: «es el espacio ocupado por la sociedad el que ha dado la materia de la categoría del espacio».

Diferenciar de acuerdo con las circunstancias y situaciones de ocupación del espacio, ha permitido contestar más fácilmente a las grandes preguntas sobre el desarrollo de las ciudades, relativas al consumo o apropiación del espacio, al gasto energético, a la calidad de vida, el costo del desarrollo peri-urbano, al nivel de servicios ofrecidos a los habitantes. El examen realizado por científicos y especialistas en el análisis de la ocupación del territorio facilita establecer categorías tales como: espacios naturales, espacios urbanos, espacios periurbanos.

Cada una de estas categorías tiene a la vez fuera de su propia identidad, subdivisiones y estructuras jerárquicas menores.

Los espacios naturales reagrupan los espacios protegidos en los que no se origina ninguna explotación económica, fuera de la de preservar los recursos de flora, fauna y limita su utilización a fines recreativos y culturales. En otros los hombres no establecen ni su vivienda, ni su empresa. Igualmente dentro de ellos se agrupan los espacios agrícolas, subdivididos en espacios de cultivo y pastoreo.

Los espacios urbanos se subdividen y agrupan a su vez según categorías en: barrios (históricos-centrales), zonas especializadas por actividad (económicacultural), suburbios.

En cuanto a los espacios peri-urbanos implica un mayor grado de esfuerzo para clasificar su posición y estructura, ya que con designarlos como espacios intemedios o como espacios mixtos no es suficiente. Corresponden a las situaciones especiales, la primera como el espacio en donde predominan las casas grandes con jardines y parques y la segunda, el espacio de las casashaciendas, las casas campesinas mezcladas y dispersas entre algunas casas de citadinos, confundiéndose con el espacio urbano.

La bús queda de los dis tintos niveles espaciales y su caracterización nos permite establecer la importancia del espacio en la planificación urbana y regional; pues, hablar del es pacio es no solo hablar de un producto, de un objeto que tiene una estructura dinámica, es también referirse al acondicionamiento de es te objeto.

Cualquier espacio se halla organizado, pero tal organización depende de múltiples factores de índole natural social y de unas políticas que influyan tanto en lo económico como en lo social, traducido en un aprovechamiento racional de los 
recursos. Igualmente es la toma de conciencia y de una actitud por parte de los grupos humanos que lo habitan, en la utilización de dichos recursos y su conservación para el futuro.

En consequencia, el análisis espacial no es un simple inventario o la mezcla de elementos físicos y de actividades humanas, sino que se trata del estudio de su significado y de su dinámica, puesto que en él ocurren cambios y evoluciona para servir de soporte a complejos sistemas de relaciones de origen natural y antrópico que se desarrollan en un contexto espacial dado.

La organización del espacio no debe ser considerada como un concepto aislado ni como un concepto dominante. De esta manera no es suficiente formular planes de urbanismo, hay que tener un claro y preciso concepto de ciudad; no es suficiente trazar vías de comunicación a través de un país; es necesario inscribirlas dentro de la geografía prospectiva, de las actividades; no es suficiente tomar medidas de descentralización (política, industrial), hay que asegurarse que dichas medidas encontrarán un medio propicio a las necesidades funcionales.

La organización del espacio no debe considerarse como el final feliz de una historia, sino como el medio para responder tal como lo formulara algún pensador «el acondicionamiento del territorio es el acondicionamiento de nues tra sociedad».

¿Deben seguir las ciudades siendo devoradoras del espacio, despilfarradoras de energía y sumamente costosas en cuanto a su funcionamiento y su gestión?

\section{REFERENCIAS BIBLIOGRÁFICAS:}

Bachelard, G. (1958) La poética del espacio, París. Bollnow, F. (1969) Hombre y Espacio. Ed. Labor Barcelona

Castells, M. (1970) Structures Sociales et Processus d'urbanization, Anales Economies, Societes, Civilizations.

Dollfus, 0. (1978) El Análisis geográfico, Barcelona, Ed Oikos-Tau

Durkheim, E. Las formas elementales de la vida religiosa. Ed. Schapiro S.R.L.. Buenos Aires.

Harvey, D. (1979) Urbanismo y Desigualdades Socia les, México, Siglo XXI ed. Puyol, R. (1982) Población y espacio, Madrid, Cincel S.A. 